\title{
Overall ICT Footprint and Green Communication Technologies
}

\author{
(Invited Paper) \\ Willem Vereecken, Ward Van Heddeghem, Didier Colle, Mario Pickavet and Piet Demeester \\ Ghent University - IBBT, Department of Information Technology (INTEC) \\ Gaston Crommenlaan 8, Bus 201, 9050 Ghent, Belgium \\ email: firstname.lastname@intec.ugent.be \\ web: www.intec.ugent.be
}

\begin{abstract}
Green communication technologies currently receive a lot of attention. In this paper we give an overview of the environmental issues related to communication technologies en present an estimation of the overall ICT footprint. Additionally we present some approaches on how to reduce this footprint and how ICT can assist in other sectors reducing their footprint.
\end{abstract}

\section{INTRODUCTION}

In its communication 'Addressing the challenge of energy efficiency through Information and Communication Technologies' the European Commission states[1]:

\section{Information and Communication Technologies have} an important role to play in reducing the energy intensity and increasing the energy efficiency of the economy, in other words, in reducing emissions and contributing to sustainable growth. In order to achieve the ambitious targets set and meet the challenges ahead, Europe needs to ensure that ICTenabled solutions are available and fully deployed.

With this statement the commission acknowledges the opportunities Information and Communication Technology (ICT) has to offer in reducing the energy intensity of the economy but also points out that ICT needs to lead by example in increasing its energy efficiency. This increase in energy efficiency needs to take place in a rapidly expanding sector. Currently the transmitted data volume increases by a factor of approximately 10 every 5 years.

In this paper we elaborate on the environmental footprint of ICT and the possibilities ICT has in environmental footprint reduction. We will demonstrate that this environment footprint encompasses more than only energy efficiency. Then, we assess this footprint and discuss some strategies to mitigate it.

\section{WHAT IS GREEN COMMUNICATIONS?}

\section{A. Types of environmetal impacts}

When discussing green technologies a lot of terms are often used and misused. One of the key issues when discussing green communications is what is exactly meant with 'green' communications. It is reasonable to assume that a synonym for 'green' is 'environmentally friendly'. But environmentally friendly is a broad term. Due to the problem of global warming and the associated climate change, the carbon emissions currently receive most attention. However, when regarding an environmentally friendly solution, issues like air, water and soil quality, protection of the ozone layer, use of natural resources, waste reduction etc. need to be considered as well.

Telecommunications equipment typically contains a considerable amount of scarce materials and heavy metals. Both the extraction of these materials, typically through mining, and the treatment of the waste represent a large environmental challenge. In table I we have presented some of the main materials which can be found in a typical PC [2]. Next to it we have displayed the average ore enrichment factors and their recyclability [3] [4]. The ore enrichment factor represents the mass in waste relative to the mass in usefull material in a mining ore. From these numbers we have derived the amount of waste produced with and without material recycling.

We see that without recycling $12 \mathrm{~kg}$ of useful material for the computer results in $500 \mathrm{~kg}$ of mining waste while with recycling this is $93 \mathrm{~kg}$. This exercise is very crude and does not incorporate other effects like for example highly acidic waste water due to the extraction chemicals. It does however clearly demonstrate that considering the material streams is important while evaluating green communications.

The impact of recycling is also clearly demonstrated in the above exercise. In reality, a good recycling strategy is considered as part of the waste hierarchy where it is only the third step (Fig. 1). This means that when considering green technologies the entire life cycle has to be taken into account. A life cycle analysis considers material extraction, production, use, transport and end-of-life as the five phases in the life cycle of a product and all phases should be considered in order to have a complete view of the environmental impact of a product.

Next to the concerns about material use in ICT there is the subject of energy consumption. Energy consumption is closely related to carbon emissions. More accurately, when discussing carbon emissions one should consider the anthropogenic greenhouse gas $(\mathrm{GHG})$ emissions. The Kyoto protocol stated 6 major GHGs: carbon dioxide $\left(\mathrm{CO}_{2}\right)$, methane $\left(\mathrm{CH}_{4}\right)$, nitrous oxide $\left(\mathrm{N}_{2} \mathrm{O}\right)$, sulfur hexafluoride $\left(\mathrm{SF}_{6}\right)$, $\mathrm{HFCs}$, and PFCs. These GHGs all have a different global warming po- 


\begin{tabular}{|c|c|c|c|c|c|}
\hline Material & Mass $(\mathrm{g})$ & Enrichment factor & Waste without recycling $(\mathrm{g})$ & Recyclability & Waste with recycling $(\mathrm{g})$ \\
\hline iron & 8090 & 3.3 & 26697 & 0.8 & $\overline{5339.4}$ \\
\hline copper & 2005 & 110 & 220550 & 0.9 & 22055 \\
\hline lead & 996.5 & 39 & 38863.5 & 0.95 & 1943.175 \\
\hline aluminum & 820 & 2.9 & 2378 & 0.8 & 475.6 \\
\hline tin & 67 & 2900 & 194300 & 0.7 & 58290 \\
\hline zinc & 21 & 300 & 6300 & 0.3 & 4410 \\
\hline nickel & 17.25 & 39 & 672.75 & 0.8 & 134.55 \\
\hline silver & 1.75 & 2600 & 4550 & 0.98 & 91 \\
\hline gold & 0.53 & 2500 & 1325 & 0.99 & 13.25 \\
\hline platinum & 0.066 & 770 & 50.82 & 0.8 & 10.164 \\
\hline \multirow[t]{2}{*}{ chromium } & 0.05 & 2.3 & 0.115 & 0 & 0.115 \\
\hline & $12 \mathrm{~kg}$ & & $500 \mathrm{~kg}$ & & $93 \mathrm{~kg}$ \\
\hline
\end{tabular}

MATERIALS AND RELATED ORE WASTES IN A PC

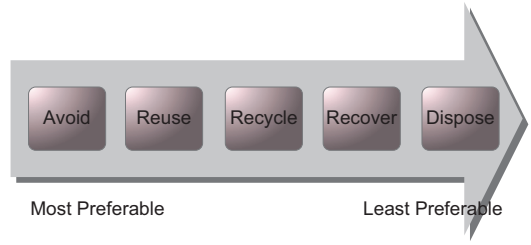

Figure 1. The waste hierarchy

\begin{tabular}{lc} 
Greenhouse gas & Global Warming Potential $(\mathrm{CO} 2 \mathrm{e})$ \\
\hline \hline Carbon dioxide $\left(\mathrm{CO}_{2}\right)$ & 1 \\
Methane $\left(\mathrm{CH}_{4}\right)$ & 25 \\
Nitrous oxide $\left(\mathrm{N}_{2} \mathrm{O}\right)$ & 298 \\
Sulfur hexafluoride $\left(\mathrm{SF}_{6}\right)$ & 22800 \\
$\mathrm{HFCs}$ & $124-14800$ \\
PFCs & $7390-12200$ \\
\hline
\end{tabular}

Table II

GLOBAL WARMING POTENTIAL OF MAIN GREENHOUSE GASSES [5]

tential (GWP) considered for a hundred years horizon. These GWPs are expressed relative to the GWP of carbon dioxide in $\mathrm{CO} 2 \mathrm{e}\left(\mathrm{CO}_{2}\right.$ equivalent). For example, for methane, which has a GWP of 25 , an emission with 1 ppmv (parts per million by volume) of methane is equivalent to an emission with 25 ppmv of carbon dioxide. The GWP of the 6 major GHGs is presented in Table II.

When regarding the energy consumption of ICT equipment this energy consumption is exclusively in electricity consumption (in the use phase of the life cycle). Based on global electricity production statistics, an average of $500 \mathrm{~g}$ $\mathrm{CO} 2 \mathrm{e} / \mathrm{kWh}$ is emitted. However, in reality the $\mathrm{CO} 2 \mathrm{e}$ emissions per $\mathrm{kWh}$ vary depending on the country or region where the electricity is produced. For example, in Australia the emissions are approximately $875 \mathrm{~g} \mathrm{CO} 2 \mathrm{e} / \mathrm{kWh}$ while in Iceland the emissions are virtually 0 . This is due to the technologies used for energy production. Coal and gas installations emit typically between 800 and $950 \mathrm{~g} \mathrm{CO} 2 \mathrm{e} / \mathrm{kWh}$ while renewables do not emit greenhouse gasses. The greenhouse gas emissions for nuclear power are also very low, but this energy source has other environmental issues related to it such as the treatment of nuclear waste.

\section{B. Direct and indirect impacts}

When analyzing environmentally friendly solutions there are both the direct and indirect impacts to consider. Direct impacts are directly related to the implementation of the considered solution. For example, implementing a solution which reduces the energy consumption of a service results in a direct impact.

Indirect impacts of solutions are related to the broader consequences of the adoption of the solution. For example, adoption of email may lead to a higher environmental impact of ICT but at the same time reduce the number of letters being sent which in turn leads to less impact of transport, paper usage, etc. Indirect impact reduction typically has a higher potential in limiting environmental issues. However, these reductions are harder to predict as they are dependent on political, fincancial, informational and behavioral factors.

Related to this we wish to point out the rebound effect. A very common strategy in limiting environmental impacts is increasing efficiency. For example, increasing the distance travelled per unit of fuel for a car. The rebound effect states that this increased efficiency decreases the associated cost as well. This will lead to a higher usage of the solution and in turn an increased impact. If we again consider the adoption of email, one could state that by replacing every letter sent by an email we are largely reducing the impact of those letters. There is however not a one-on-one relation between the number of emails sent and the number of letters written before email was adopted. This case demonstrates that prediciting the indirect environmental impacts of soltutions is a difficult excersise which has to be caried out with great care.

\section{THE FOOTPRINT OF ICT}

\section{A. Energy consumption of ICT}

After some general considerations in the previous section we want to analyze the energy consumption of ICT in some more detail. We distinguish five categories of equipment. First of all there is the data center equipment which comprises computing, storage and network equipment in data centers, but additional supporting equipment like HVAC (Heating Ventilation and Air Conditioning) and UPS (Uninteruptable Power Supply) as well. Secondly we consider the PCs which 


\begin{tabular}{lccc} 
Category & $\begin{array}{c}\text { Power cons. } \\
2008(\mathrm{GW})\end{array}$ & $\begin{array}{c}\text { Growth rate } \\
\text { (p.a.) }\end{array}$ & $\begin{array}{c}2020 \text { prediction } \\
(\mathrm{GW})\end{array}$ \\
\hline \hline Data centers & 29 & $12 \%$ & 113 \\
PCs & 30 & $7,5 \%$ & 71 \\
Network Equipment & 25 & $12 \%$ & 97 \\
TVs & 44 & $5 \%$ & 79 \\
Other & 40 & $5 \%$ & 72 \\
\hline Total & 168 & & 433 \\
& & & \\
Worldwide Electricity & 2350 & $2,0 \%$ & 2970 \\
ICT fraction & $7,15 \%$ & & $14,57 \%$ \\
\hline \hline
\end{tabular}

Table III

WORLDWIDE ICT POWER CONSUMPTION

comprise both laptops and desktop computers. The third category contains all network equipment like switches and routers but also modems and home gateways. Network interface cards are not considered in this category as they are either accounted for in PCs or data centers. TVs, including additional equipment like DVD players are a fourth category and finally we consider all other devices like telephones, mobile phones, printers, fax machines, etc. as a fifth category.

In a study elaborated in [6] we have analyzed the worldwide electricity consumption of the equipment in these five categories for 2008 and their respective growth levels in order to predict a business as usual case for 2020. We have compared this with the global energy and electricity consumption levels [7]. These numbers are summarized in table III.

From this table we can already draw some main conclusions. First of all, the power consumption is fairly equally distributed between the different categories. This means that in order to realize large optimizations in the ICT power consumption, all these categories need to be tackled. It also implies that when evaluating solutions one should investigate the impact in all these areas. For example, if a new networking technology reduces the power consumption in the network, one should check if the reductions are not neutralized by larger power consumptions in the data center or in the PC.

We also see that ICT consumes about $7 \%$ of the electricity consumption. This in itself is already a fair fraction. However, the projection that this fraction will double by 2020 in a business as usual scenario (even with electricity production growth rates accounted for) indicates that this growth scenario is not sustainable. In section IV we will indicate how this scenario can be avoided.

Power consumption in data centers: The power consumption in data centers primary originates from the power consumption of servers. There is a wide variety of servers available ranging from small servers with capabilities comparable to a personal computer to large supercomputers. Furthermore there are different types of servers optimized for specific tasks such as web servers and database servers.

One of the largest problems of these servers is the relative independence of the power consumption on the server load. This combined with the fact that many servers are being operated far below their actual capacity leads to a lot of wasted energy in the servers in data centers.

Secondly, a significant fraction of the power consumption originates from operational overhead such as cooling, UPS and lighting. This power consumption shows a large correlation with the power consumption of the ICT equipment. Therefore, an efficiency metric for data centers is defined by the Green Grid: The power usage effectiveness (PUE) which expresses the total facility power divided by the power consumption of the ICT equipment [8].

A typical value for the PUE of data centers is estimated to be approximately 2.0. This is highly dependent on the type of data center. First of all the size of the data center has an influence. Larger data centers tend to be able to implement more efficient cooling. On the other hand, availability requirements may necessitate the use of more expensive UPS and more redundancy in the data center support which then results in a higher PUE.

Power consumption in communication networks: When analyzing the power consumption in telecommunication networks we make a distinction between the customer premises equipment (CPE), access networks and core networks.

Core networks are the internet highways of the telecommunication networks. They are built to interconnect different sites and aggregate the traffic between these sites. In order to provide resilience in case of a defect they typically have a mesh structure. Core networks are built on many levels covering areas ranging from small cities to global, international networks.

Access networks are built to provide the user's connection to the network. They are typically built in a tree structure. We distinguish fixed access networks in which the user is connected to the network by a cable and wireless access networks which use radio waves. Fixed access networks typically provide higher bandwidths to the user but have a fixed connection point. Wireless access networks allow a larger mobility to the user. Therefore we also speak of mobile access networks. These networks however have a smaller access bit rate.

In order to connect the user to the access network he typically uses a home gateway (e.g. the modem). This home gateway contains the functionality for the user to connect different devices like a PC, a laptop or a TV.

In [9] we can find the breakdown of the network power consumption of a typical operator. It shows that half of the operational power consumption is used for the fixed line access network and about one fifth for the mobile access network. The aggregation and backbone network (which we here consider to be core networks) represent a much smaller fraction. This is confirmed by [10], but the author also indicates that with the increasing access network bitrates, the power consumption of the core network could rise much faster than the access network.

In table IV we have indicated the per user power consumption for customer premises equipment and access networks for 


\begin{tabular}{cccccc} 
& Access bitrate & \multicolumn{2}{c}{ Access Network } & \multicolumn{2}{c}{ CPE } \\
& (DS Mbps) & Model & CoC & Model & CoC \\
\hline \hline ADSL2 & 12 & 2.8 & 1.2 & $3-10$ & $3.8-5.0$ \\
VDSL2 & 100 & 5 & $1.6-2.5$ & $5-10$ & $6.0-7.5$ \\
GPON & $38.9-77.8$ & $0.12-0.8$ & 0.25 & $3.0-10$ & $7.7-9.7$ \\
\hline \hline
\end{tabular}

Table IV

PER USER POWER CONSUMPTION (WATT/USER) OF FIXED LINE ACCESS NETWORK TECHNOLOGIES.

several access network technologies, together with the access bitrate in downstream (DS). We have based the numbers on datasheets of several types of network equipment, measurements of network equipment and other studies. Next to these numbers we have also compared them to values given by the code of conduct $(\mathrm{CoC})$ for broadband equipment of the European commission[11].

First of all we see that Digital Subscriber Line (DSL) technologies consume more power in the access network than Gigabit Passive Optical Network (GPON) technology, whereas GPON technology will allow for higher bitrates. Note that the given access bitrate for GPON is based on the sharing of 2.5 Gbps by 32 or 64 users, in reality, due to traffic aggregation, the user will be able to obtain higher peak bitrates. We also see that for DSL technologies the modelled power consumption is higher than the proposed power consumption by the code of conduct. This is related to the maturity of these technologies. In recent equipment lower power consumption is achievable, however, in reality older, more power consuming equipment is still used. For GPON technologies, which are less mature, the code of conduct allows the use of more power consuming equipment whereas lower power consumption rates are possible.

On the other hand we see that the power consumption is dominated by the customer premise equipment. Note that for DSL technologies the numbers given by the code of conduct are significantly lower than the equipment used. The analysis above is still valid. However, the code of conduct uses a slightly more complex model in which it attributes power consumption values for each functionality of the home gateway. Here, we only cited the numbers for the core functionalities whereas we measured equipment with additional functionalities.

For mobile access networks the analysis is less straightforward. In [12] we have analyzed the power consumption of base stations for Fixed WiMAX, Mobile WiMAX and UMTS in relation to coverage in a suburban area. We have displayed the range and power consumption of the base stations in table $\mathrm{V}$. The numbers are for a guaranteed bit rate of $2 \mathrm{Mbps}$. Closer to the base stations, due to different modulation schemes, higher bit rates are achievable.

The comparison of this power consumption with fixed line technologies is not straightforward. For fixed line access networks, a permanent physical connection has to be made to the user. Thus, the power consumption of the access network is highly correlated with the number of subscribers, and the

\begin{tabular}{rcc} 
& Power BS $(\mathrm{kW})$ & Range $(\mathrm{km})$ \\
\hline \hline Fixed WiMAX & 2.9 & 0.43 \\
Mobile WiMAX & 2.9 & 0.75 \\
UMTS & 5.6 & 1.0 \\
\hline \hline
\end{tabular}

Table V

POWER CONSUMPTION AND RANGE OF BASE STATIONS (BS) FOR A BIT RATE OF 2 MBPS

power per user is a stable value for a certain technology. Mobile access networks are designed to cover a certain area, and interconnect the users in that area. Thus, the power consumption per user is dependent on the user density of the covered area.

If we assume a user density of 300 users $/ \mathrm{km}^{2}$, we get a per user power consumption of approximately 16.5 Watt/user for fixed WiMAX, 5.5 Watt/user for mobile WiMAX and 6.0 Watt/user for UMTS. This is higher than the power consumption for fixed line access networks. We need to consider however that for mobile access networks there is often no home gateway to be considered. The user needs to be mobile and the client device is therefore typically a mobile phone or a USB dongle. These devices are optimized for a low power consumption in order to achieve long autonomy. When comparing the power consumption for access network and CPE in this scenario the power consumption per user is comparable between fixed line technologies and mobile technologies.

When we however consider only half the user density (or two mobile access networks from competing operators covering the area) the per user power consumption of the mobile access network immedeately doubles. This leads to entirely different conclusions for the power consumption of mobile access networks.

As already indicated the power consumed in the core network is only a small fraction of the power consumed in the access network. The power consumption of the core network is largely defined by the routers interconnecting the different sites. In Fig. 2 we have displayed the power consumption of core routers based on datasheets found in [13]. We see that for higher throughputs the routers consume more power. However, smaller routers tend to be located near the edge of the core network whereas the larger routers are more central in the core network where the traffic is more aggregated. Therefore we consider the power consumption per bit rate. This reveals that the larger routers consume less energy per bit than the edge routers. When aggregating over the entire core network, the power consumption will also be the largest at the edge of the network and smaller in the centre.

\section{B. Life cycle impact of ICT}

Until now we have only considered the power consumption in the use phase of ICT equipment. However, as stated in section II, it is important to consider the entire life cycle impact of devices. Life cycle assessments typically cover a complex process in a large area so we limit ourselves in this 


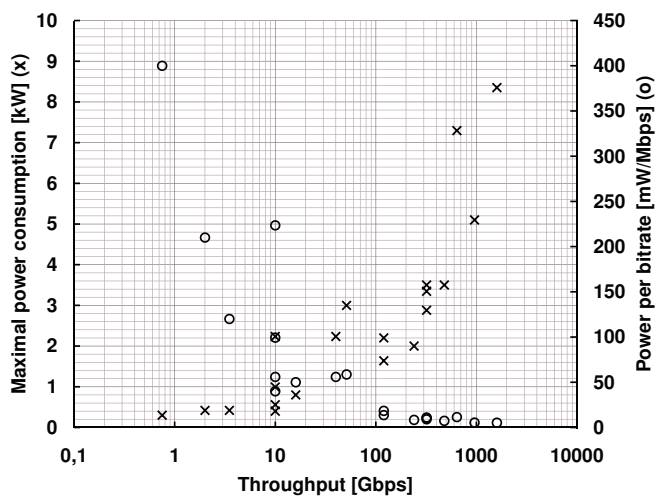

Figure 2. Maximal Power consumption $(x)$ and power per bitrate (o) of routers versus the maximal throughput

section to a few trends.

In [14] some typical ICT equipment is compared focussing on GHG emissions during its life cycle. It shows that the main phases to consider are manufacturing and use phase. Numbers for material extraction phase are not provided. The use phase is assumed to span 4 years. The only source of GHG emissions in the use phase is power consumption.

In order to make the evaluation easier we define the manufacturing overhead the GHG emissions in the manufacturing phase divided by the GHG emissions in the use phase. For a laptop PC the manufacturing overhead is 0.6 . For a server this is 0.5 . For a mobile phone on the other hand the manufacturing overhead is 5 meaning the manufacturing emits five times the emissions of the use phase.

Another study [15] conducted a life cycle assessment of the telecommunications sector. The aim of the study is comparable to [6] but has a smaller scope in the considered equipment. This study shows that for data centers the manufacturing overhead is approximately 0.2 . For fixed line networks it is closer to 0.25 and for mobile networks it is approximately 0.5 .

\section{Mitigating The ICT FOOTPRINT}

\section{A. Direct impacts}

When mitigating the direct impacts we want to limit the footprint of ICT as much as possible. While limiting this footprint we want to maintain the same level of service. First of all, we wish to limit the power consumption of the equipment. Since we have indicated that in ICT there is no dominant category of equipment consuming power it is important to assess this for the overall solution.

Next to limiting the power consumption it is also important to decrease the life cycle impact of the solution. Since the manufacturing phase in ICT has a large impact, one of the most straightforward ways of reducing life cycle impact is increasing the time span of the use phase of the equipment. Clearly, when doubling this time span this immediately divides the impact of the manufacturing phase by two.
The above principles need to be applied with the appropriate scrutiny and often a balance needs to be found between power consumption, equipment use time and rendered service. Nonetheless, achieving optimizations in both areas is a good indicator of the achieved footprint reduction.

In order to reduce the power consumption of networks Gupta and Singh [16] suggested the introduction of sleep modes in the network which allows for machines to switch off. Nordman and Christensen [17] expanded their work to come with an overall approach of reducing the energy consumption of networks. However, the explained principles are applicable on the broader context of ICT.

First of all, they focus on a component level where more efficient technologies should be used. A clear example of this principle is the use of optical access networks instead of DSL technologies. The optical technology allows for both a lower power consumption and higher bandwidth delivered to the user. Also in the core network full optical switching is investigated instead of electronic switching [18].

Next to using optimized components a second level of optimization lies in power management. Within power management, three approaches are suggested: do less work, slow down and turn off idle elements.

Do less work - In this strategy the processes are optimized so the load to be executed becomes minimal resulting in lower power consumption. An example is the optical bypassing of routers so less packets need to be processed by the router.

Slow down - The faster a process, the more resource intensive it becomes. In complex processes, the speeds of several subprocesses don't match and thus resources are used without being absolutely required. There are two ways of slowing down processes. They can be ran with adaptive speeds, selecting the minimal required speed to execute the process in time. On top of that one can introduce buffering. Instead of running a process immedeately upon arrival, one can store tasks until a buffer is full and then execute them in bulk. This allows for components to be temporarily switched off resulting in lower power consumption.

Turn off idle elements - When elements are idle their power consumption is obviously wasteful. Turning these elements off leads to less power consumption. For example, when operating a core network there can be a difference of traffic load between night and day. Turning off certain links during low traffic operation can lead to significant optimizations [19].

We wish to point out that the above principles can lead to lower life cycle impacts. When equipment is designed for power management, the strain will be less and the equipment will last longer. Second, the requirement for less high performing equipment leads to the possibility of using older equipment and thus longer use of the equipment or reusability for different applications.

The above analysis focuses on optimizing the used infrastructures. Therefore, besides optimizing components and power management, we want to focus on redesigning the solutions. When considering the service a certain infrastructure 
renders rather than the functionality serious optimizations can be achieved. When we consider for example the service rendered by a desktop computer we see that a lot of equipment is used for sometimes very simple services rendered to the user. When we replace the desktop by a thin client solution we can group the computational power in a data center which is easier to optimize and power manage [20].

This kind of paradigm shifts can have large potential energy savings but requires thorough modeling and has a high uncertainty in the actual energy saving realized.

Besides optimizing the energy consumption an additional gain in footprint reduction can be achieved by controlling the source of the used energy. Especially data centers, which are energy consumption hotspots, can be optimized in this direction. Locating these data centers near sources of green energy production leads to a lower footprint. Additionally, using communications technologies, one can opt to migrate processes between data centers according to the availability of green energy for example based on day-night cycles (follow the sun) or availability of wind (follow the wind) [21].

\section{B. Indirect impacts}

ICT can also be an enabler in reducing the global footprint. The strength of ICT, and especially telecommunications is that it dematerializes streams. Examples are e-mail, tele-working, tele-conferencing, etc. Information technology can be used to provide users with information about the energy consumption of systems as well. On top of that ICT can provide services to power manage these systems and thus reduce the impact. These so called smart grids are considered as a way to enable more green electricity production technologies to supply power to the electricity grid.

Overall, the potential energy savings are estimated to be approximately five times ICT's own footprint[22]. However, as stated before, this potential is largely dependent on adoption parameters which are beyond the control of the ICT itself.

\section{Conclusion}

There are some important environmental concerns related to ICT. Especially the growth scenarios for the sector indicate that it is important to develop strategies to limit the environmental footprint. These strategies need to focus on reducing the power consumption but also reducing the complete life cycle impacts of the equipment. On the other hand, ICT has a large potential in reducing power consumption in other sectors. However, this potential is dependent on political, fincancial, informational and behavioral factors which are difficult to predict.

\section{ACKNOWLEDGMENT}

The work described in this paper was carried out with support of the IBBT-project GreenICT and the BONE project ("Building the Future Optical Network in Europe"), a Network of Excellence funded by the European Community's Seventh Framework.

\section{REFERENCES}

[1] European Commission, "Addressing the challenge of energy efficiency through information and communication technologies," 2008.

[2] E. Williams, R. Kahhat, B. Allenby, E. Kavazanjian, J. Kim, and M. Xu, "Environmental, social, and economic implications of global reuse and recycling of personal computers," Environmental Science \& Technology, vol. 42, pp. 6446-6454, 2008.

[3] K. Spitz and J. Trudinger, Mining and the Environment: From Ore to Metal. CRC Press, 2008.

[4] "United states geological services," http://www.usgs.gov/.

[5] P. Forster, V. Ramaswamy, P. Artaxo, T. Berntsen, R. Betts, D. Fahey, J. Haywood, J. Lean, D. Lowe, G. Myhre, J. Nganga, R. Prinn, G. Raga, M. Schulz, and R. V. Dorland, Climate Change 2007: The Physical Science Basis. Contribution of Working Group I to the Fourth Assessment Report of the Intergovernmental Panel on Climate Change. Cambridge, United Kingdom and New York, NY, USA: Cambridge University Press, 2007, ch. Changes in Atmospheric Constituents and in Radiative Forcing, pp. $130-234$.

[6] M. Pickavet, W. Vereecken, S. Demeyer, P. Audenaert, B. Vermeulen, C. Develder, D. Colle, B. Dhoedt, and P. Demeester, "Worldwide energy needs for ict: The rise of power-aware networking," in Advanced Networks and Telecommunication Systems, 2008. ANTS '08. 2nd International Symposium on, Dec. 2008, pp. 1-3.

[7] International Energy Outlook 2009. Energy Information Administration, 2009, ch. Electricity, pp. $63-84$.

[8] The Green Grid, "Green grid metrics: Describing datacenter power efficiency," 2007.

[9] A. Gladisch, C. Lange, and R. Leppla, "Power efficiency of optical versus electronic access networks," in Optical Communication 2008, ECOC '08. 34th European Conference and Exhibition on, 2008.

[10] J. Baliga, R. Ayre, K. Hinton, W. Sorin, and R. Tucker, "Energy consumption in optical ip networks," Lightwave Technology, Journal of, vol. 27, no. 13, pp. 2391-2403, July1, 2009.

[11] European Commission, "Code of conduct on energy consumption of broadband equipment version 3," November 2008.

[12] M. Deruyck, W. Vereecken, E. Tanghe, W. Joseph, M. Pickavet, L. Martens, and P. Demeester, "Power consumption in wireless access networks," in to be published in European Wireless 2010, 2010.

[13] "Juniper," http://www.juniper.net.

[14] C. Herrmann, "Environmental footprint of ict equipment in manufacture, use and end of life," in Optical Communication 2008, ECOC '08. 34th European Conference and Exhibition on, 2008.

[15] J. Malmodin, "Carbon footprint of mobile communications and ict," in Joint International Congress and Exhibition Electronics Goes Green, 2008.

[16] M. Gupta and S. Singh, "Greening of the internet," in SIGCOMM '03: Proceedings of the 2003 conference on Applications, technologies, architectures, and protocols for computer communications. New York, NY, USA: ACM, 2003, pp. 19-26.

[17] K. Christensen and B. Nordman, "Reducing the energy consumption of networked devices," in IEEE 802.3 tutorial, 2005.

[18] S. Aleksic, "Analysis of power consumption in future high-capacity network nodes," Optical Communications and Networking, IEEE/OSA Journal of, vol. 1, no. 3, pp. 245-258, August 2009.

[19] B. Puype, W. Vereecken, D. Colle, M. Pickavet, and P. Demeester, "Power reduction techniques in multilayer traffic engineering," in Transparent Optical Networks, 2009. ICTON '09. 11th International Conference on, 28 2009-July 2 2009, pp. 1-4.

[20] W. Vereecken, L. Deboosere, P. Simoens, B. Vermeulen, D. Colle, C. Develder, M. Pickavet, B. Dhoedt, and P. Demeester, "Power efficiency of thin clients," submitted to European Transactions on Telecommunications, 2010.

[21] S. Figuerola, M. Lemay, V. Reijs, M. Savoie, and B. St. Arnaud, "Converged optical network infrastructures in support of future internet and grid services using iaas to reduce ghg emissions," Lightwave Technology, Journal of, vol. 27, no. 12, pp. 1941-1946, June15, 2009.

[22] M. Webb, "Smart 2020: Enabling the low carbon economy in the information age," The Climate Group, Tech. Rep., 2008. 